\title{
Non-occurrence of free-living Paramoeba invadens in water and sediments of Halifax Harbour, Nova Scotia, Canada
}

\author{
J. F. Jellett*, J. A. Novitsky, J. A. Cantley, R. E. Scheibling \\ Biology Department, Dalhousie University, Halifax, Nova Scotia, Canada B3H 4J1
}

\begin{abstract}
Seawater and sediment samples from various sites in or near Halifax Harbour were cultured for Paramoeba, as were tissues of the natural sea urchin host Strongylocentrotus droebachiensis sampled from Halifax Harbour. An isolate of Paramoeba from a Halifax Harbour water sample was not virulent on injection into healthy sea urchins. However, some sea urchins in cages near the outfall pipe of Dalhousie University's seawater system were infected during the annual peak of the seawater temperature cycle. Results indicate that (1) there is no evidence of a free-living endemic population of Paramoeba invadens in or near Halifax Harbour, (2) $S$. droebachiensis, the natural host for $P$. invadens, do not harbour a reservoir population of this organism at temperatures sub-optimal for paramoebiasis, and (3) Paramoeba which are morphologically indistinct from laboratory stocks of $P$. invadens were recovered near the outfall pipe. These organisms may have been released via the outfall pipe into Halifax Harbour and subsequently lost virulence.
\end{abstract}

A pathogenic marine amoeba, Paramoeba invadens Jones, 1985, was found to be the causative agent of sea urchin Strongylocentrotus droebachiensis mass mortalities along the Atlantic coast of Nova Scotia from 1980 to 1983 (Miller \& Colodey 1983, Scheibling \& Stephenson 1984, Jones \& Scheibling 1985, Jones et al. 1985). Most species of the genus Paramoeba are freeliving and ubiquitous in the marine environment, and are commonly found in the surface microlayer, water column and bottom sediments in a range that extends from the North Atlantic to the Gulf of Mexico (Page $1970,1973,1976,1983$, Davis et al. 1978, Bovee \& Sawyer 1979, Sawyer 1980). Only 2 species in this genus are known to be parasitic (Page 1983, Jones 1985). Paramoeba perniciosa appears to be an obligate parasite (Sprague et al. 1969, Page 1983) in the blue crab Callinectes sapidus. $P$. invadens is known only

\footnotetext{
- Addressee for correspondence; present address: Department of Microbiology, Sir Charles Tupper Medical Building, Dalhousie University, Halifax, Nova Scotia, Canada B3H $4 \mathrm{H} 7$
}

from the tissues of diseased sea urchins and their surrounding seawater (Jones \& Scheibling 1985), but it can be cultured on bacteria and is therefore thought to be a free-living opportunistic parasite (Jones 1985, Jones \& Scheibling 1985, Jones et al. 1985, Jellett \& Scheibling 1988b). The only known species of freeliving Paramoeba morphologically similar to $P$. invadens is $P$. aestuarina (Page 1983). Recent observations by Rogerson (1988 and pers. comm.) may bring into question their position as different taxonomic species.

The origin (endemic or exotic) of the infective population of Paramoeba invadens involved in the sea urchin mass mortalities along the Nova Scotia coast has remained unresolved (Jones \& Scheibling 1985, Scheibling 1988).

Though field and laboratory studies (Scheibling \& Stephenson 1984, Jellett \& Scheibling 1988a), a direct relationship was found between temperature and the sea urchin disease, and between temperature and growth rates of Paramoeba invadens in monoxenic culture. These studies showed that temperatures exceeding 10 to $12^{\circ} \mathrm{C}$ are necessary for elevated growth rates of $P$. invadens in vitro and for transmission and/or progression of sea urchin paramoebiasis in vivo. However, $P$. invadens can survive, but does not grow or cause disease in sea urchins, at low temperatures (2 to $5^{\circ} \mathrm{C}$ ).

Paramoebiasis has not been seen in nature since 1983. Since that time, the disease has been maintained in vivo (in Strongylocentrotus droebachiensis) in a temperature-controlled flow-through seawater system (after Scheibling \& Stephenson 1984). The untreated effluent from the aquaria containing diseased sea urchins drains into the outflow from Dalhousie University's Aquatron system which is pumped into the Northwest Arm of Halifax Harbour.

The purpose of this study was to determine (1) if Paramoeba invadens released from the Aquatron can 
survive and maintain virulence in Halifax Harbour, (2) if $P$. invadens can be recovered from sediment or seawater away from the discharge site, thereby indicating the free-living and possibly endemic nature of this marine amoeba, and (3) if Paramoeba exists as a lowgrade (non-pathogenic) parasite in Strongylocentrotus droebachiensis at temperatures which are sub-optimal for disease occurrence.

Methods. Bottom and surface seawater samples were collected on July 21, 1987 from the following locations in Halifax Harbour: at the outfall of the Dalhousie Aquatron seawater system in the Northwest Arm (Fig. 1, Site 6), $30 \mathrm{~m}$ north and south of the outfall, $60 \mathrm{~m}$ north and south of the outfall, and at Eastern Passage (Fig. 1, Site 11). In addition, between September 10 and 15. 1987, nearshore surface seawater samples were collected from a total of 14 sites in and around Halifax

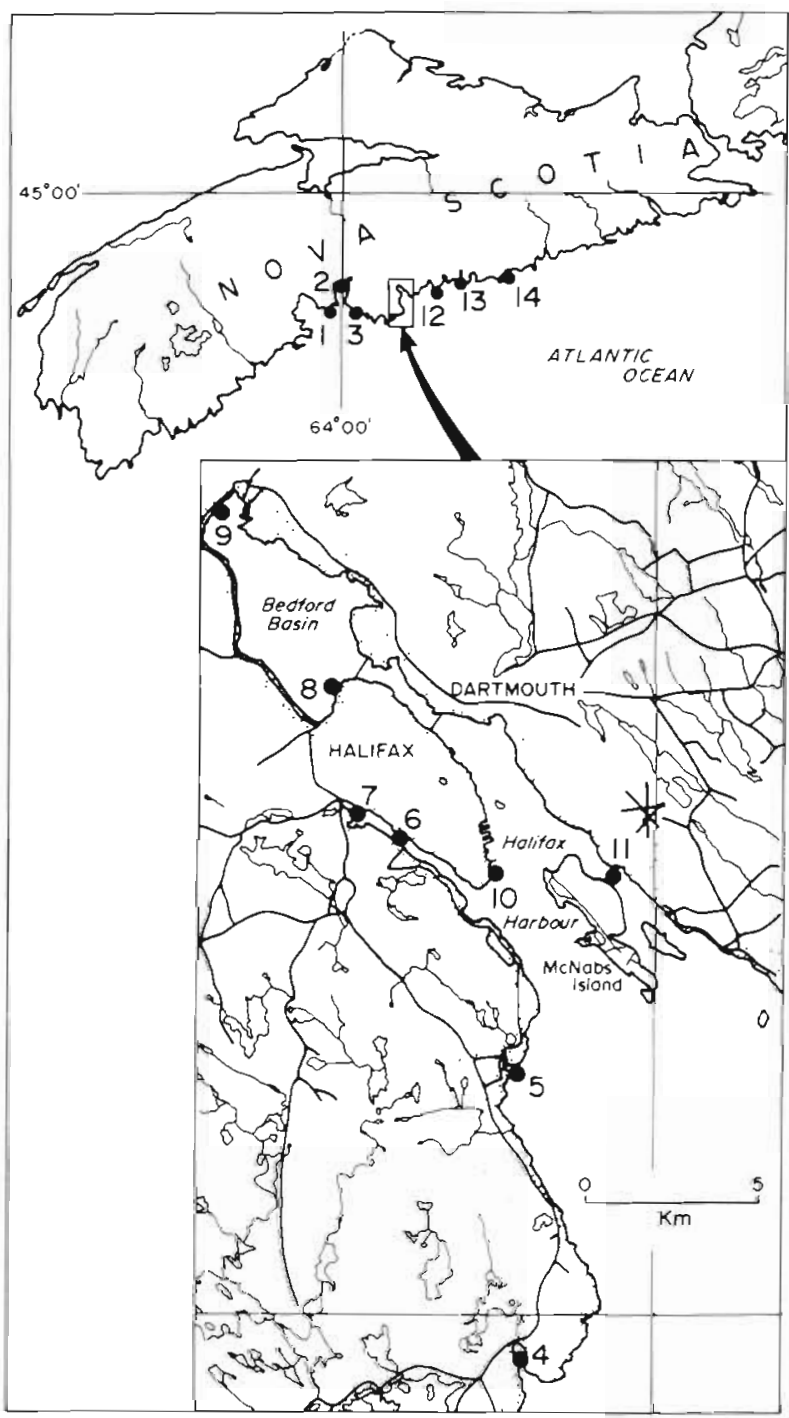

Fig. 1. Sampling locations (Sites 1 to 14) in (inset) and around Halifax Harbour Aquatron outfall is Site 6
Harbour (Fig. 1). Surface water samples were collected by hand in clean polypropylene bottles at all sites Bottom water samples ( $1 \mathrm{~m}$ off the bottom) were collected at $7.6 \mathrm{~m}$ at the outfall sites using a Kemmerer sampler fitted with a thermometer, and at $21 \mathrm{~m}$ at Eastern Passage using SCUBA. All seawater samples were gravity-filtered through $5 \mu \mathrm{m}$ membrane filters (Millipore Type SM) to the maximum volume filterable before clogging (660 to $2300 \mathrm{ml}$ ).

Paramoeba was cultured by placing the filters onto artifical seawater (ASW) agar (Jellett \& Scheibling $1988 \mathrm{~b}$ ) in $100 \mathrm{~mm}$ disposable plastic petri dishes with ca $20 \mathrm{ml}$ of ASW overlay (after Page 1983). Cultures were incubated at $15^{\circ} \mathrm{C}$ for $3 \mathrm{wk}$ in complete darkness. The cultures were inspected using phase contrast microscopy $(400 \times)$ for amoebae. Cultures containing amoebae conforming in size and morphology to Paramoeba (Page 1983) were examined at $1000 \times$ with differential interference contrast optics to confirm the presence of one or more parasomes, the identifying feature of the genus Paramoeba. The estimated minimum number (EMN) of Paramoeba in the sample was determined by assuming the presence of at least one Paramoeba per original volume of filtered seawater in positive cultures, and in negative cultures as less than one Paramoeba per volume of filtered seawater. All filtered volumes were then equated to $1 \mathrm{l}$ for comparison.

Using a micromanipulator, a single Paramoeba was isolated from a culture from outfall bottom water and grown on $1.2 \%$ ASW agar preinoculated with Pseudomonas nautica as a food source (after Jellett \& Scheibling 1988b). Infection experiments with this environmental isolate of Paramoeba (from the outfall) were performed by the method of Jones \& Scheibling (1985). Individuals in 2 groups of 5 sea urchins Strongylocentrotus droebachiensis were each injected with $1.0 \mathrm{mI}$ of antibiotic-treated Paramoeba from culture containing 1240 amoebae $\mathrm{ml}^{-1}$. Antibiotics $\left(100 \mathrm{IU} \mathrm{ml}^{-1}\right.$ penicillin and $100 \mu \mathrm{g} \mathrm{ml} \mathrm{m}^{-1}$ streptomycin, Gibco) suppress the bacteria which serve as the amoebic food source. As controls, individuals in 2 groups of 5 sea urchins were each injected with $1.0 \mathrm{ml}$ of antibiotic-treated $P$. nautica and individuals in another 2 groups of 5 were each injected only with $1.0 \mathrm{ml}$ of antibiotic solution. Temperature-controlled $\left(16^{\circ} \mathrm{C}\right)$ seawater flowed over each group of injected sea urchins and into a separate aquarium containing 6 healthy S. droebachiensis. Injected sea urchins and those in the aquaria (waterborne exposure) were monitored daily for signs of paramoebiasis, particularly loss of tube foot attachment (Jones \& Scheibling 1985). After 30 d all sea urchins were dissected, and a segment of each radial nerve and $1.0 \mathrm{ml}$ of coelomic flud were removed and cultured on $0.6 \%$ ASW agar for Paramoeba after the method of 
Jellett \& Scheibling (1988b). After 3 wk of incubation at $15^{\circ} \mathrm{C}$, the radial nerve and coelomic fluid samples were examined for amoebae. Radial nerve tissues from diseased sea urchins (maintained at $16^{\circ} \mathrm{C}$ in a flowthrough seawater system after Scheibling \& Stephenson 1984), and sediment samples (600 ml gravityfiltered) from aquaria containing diseased sea urchins, were cultured for Paramoeba as described above.

A preliminary experiment was performed to determine if pathogenic Paramoeba invadens were being released into Halifax Harbour via the Aquatron outfall. Between September 1 and 24, 1987, during the peak (9.9 to $16.5^{\circ} \mathrm{C}$ ) of the annual temperature cycle, vexar cages (1 $\mathrm{m}$ diameter, $40 \mathrm{~cm}$ height, $16 \mathrm{~mm}$ mesh aperture), each containing 50 healthy Strongylocentrotus droebachiensis (collected from Bedford Basin) and kelp as food, were placed on the bottom at the outfall, and at Sites 1 and $2 \mathrm{~km}$ south of the outfall. Sea urchins were monitored for signs of paramoebiasis by lifting the cages at weekly intervals and examining the urchins for loss of tube foot attachment or other abnormalities. Sea urchins showing any pathological signs were removed and dissected. Segments of each radial nerve and $1.0 \mathrm{ml}$ samples of coelomic fluid were cultured on $0.6 \%$ ASW agar for Paramoeba. After $22 \mathrm{~d}$ in the cages, all sea urchins were removed and radial nerve and coelomic fluid samples were cultured for Paramoeba as described above. Culture dishes were incubated for 3 wk at $15^{\circ} \mathrm{C}$ and then examined for amoebae.

The environmental isolate of Paramoeba and stockcultured Paramoeba invadens were further examined and photographed for comparison after staining with DAPI (Rogerson 1988) using a Wild Leitz Fluorescence microscope equipped with an A2 filter system.

One hundred apparently healthy sea urchins Strongylocentrotus droebachiensis were collected on January 21, 1988 from Bedford Basin by divers using SCUBA. Seawater temperature at the time of collection was ca $2^{\circ} \mathrm{C}$. The sea urchins were maintained in ambient, flow-through seawater. They were dissected within $7 \mathrm{~d}$ and a segment of each radial nerve and $1.0 \mathrm{ml}$ of coelomic fluid were cultured for Paramoeba. After incubation at $15^{\circ} \mathrm{C}$ for $3 \mathrm{wk}$, cultures were examined for amoebae. Any positive cultures were further examined at $1000 \times$ with differential interference contrast optics.

Results and Discussion. Diseased sea urchins have been maintained continuously in the Dalhousie seawater system (Aquatron) since October 1983 (Scheibling \& Stephenson 1984, Jones \& Scheibling 1985, Jellett \& Scheibling 1988b, Jellett et al. 1988a, b, this study). Paramoeba invadens is known to be transmitted in seawater (Scheibling \& Stephenson 1984, Jones \& Scheibling 1985) and in this study, Paramoeba was isolated from sediment collected from an aquarium containing infected sea urchins. Water and sediment from aquaria containing diseased sea urchins drains into the Aquatron outfall pipe.

The effluent from the Aquatron discharges into a blind inlet, the Northwest Arm of Halifax Harbour, which is $4.75 \mathrm{~km}$ long, receives no freshwater input and has a tidal flux of $1 \mathrm{~m}$. The outfall (Fig. 1, Site 6) is a point-source discharge situated ca $19.0 \mathrm{~m}$ offshore $0.5 \mathrm{~m}$ above the bottom at a water depth of ca $10 \mathrm{~m}$. The volume of effluent discharged from the system depends on current usage and is a mixture of both freshwater and saltwater.

Sampling locations were selected near the outfall and extending through Halifax Harbour, and for some distance north and south of the Harbour mouth (Fig. 1). The seawater from the sampling sites varied in the amount of particulate matter, which determined the volume of water able to be gravity-filtered through a 5 um filter.

Paramoeba was recovered from some morbid sea urchins which were removed from cages located on the sea bottom at the outfall and at 1 and $2 \mathrm{~km}$ south of the outfall. However, infection was not consistent at any one site nor was it restricted to the site closest to the outfall. This suggests that virulent Paramoeba invadens is released from the Aquatron outfall and can cause disease in the caged sea urchins. In previous laboratory studies (Scheibling \& Stephenson 1984, Jellett \& Scheibling 1988b), waterborne transmission of $P$. invadens at the seawater temperatures experienced at the caging sites $\left(9.9\right.$ to $16.5^{\circ} \mathrm{C}$ ) resulted in $100 \%$ mortality in Strongylocentrotus droebachiensis exposed to diseased conspecifics. However, incidence of infection by waterborne exposure or injection is known to be dosage dependent (Scheibling \& Stephenson 1984, Jellett unpubl.). Two possibilities exist which could explain the sporadic infection of caged sea urchins in this study: (1) virulent amoebae are not released in sufficient quantity (through dilution in the outfall pipe and on subsequent release), or (2) some of those that are released have lost virulence (possibly through exposure to conditions in the outfall pipe).

Free-living Paramoeba were isolated from several of the water samples collected near the outfall site (Table 1). Specifically, Paramoeba was isolated from surface water samples collected up to $30 \mathrm{~m}$, and from bottom water samples collected up to $60 \mathrm{~m}$, from the point of discharge. On one occasion, Paramoeba also was isolated from surface and bottom water samples from another site within Halifax Harbour on July 21. 1987 (Table 1; Fig. 1, Site 11). However, on subsequent resampling between September 10 and 15, 1987, no Paramoeba was isolated from nearshore seawater surface samples from this site nor from any of the other of the 13 nearshore sites except for that nearest the out- 
along the Atlantic coast of Nova Scotia was an endemic population of this organism as previously suggested (Jones \& Scheibling 1985, Scheibling 1988). Our data lend support to the alternate hypothesis (Jones \& Scheibling 1985, Scheibling 1988) that the source of $P$. invadens is more likely outside of our immediate geographic area and that the organism was introduced at the time of the epizootics with warm water currents or via other oceanographic phenomena.

Acknowledgements. This research was supported by grants to J.A.N. and R.E.S. from the Natural Sciences and Engineering Research Council of Canada. J. F. J. was supported by predoctoral fellowships from the Natural Sciences and Engineering Research Council of Canada and the Killam Trust. The authors are grateful to Roy Hirtle for assistance with micromanipulation, and to Jay Bugden and Bruce Raymond for excellent field assistance.

\section{LITERATURE CITED}

Bovee, E. C., Sawyer, I. K. (1979). Marine flora and fauna of the northeastern United States. Protozoa: Sarcodina: Amoebae. NOAA Tech. Rep. NMFS Circular 419, p. 1-56

Davis, P. G., Caron, D. A., Sieburth, J. McN. (1978). Oceanic amoebae from the North Atlantic: cultue, distribution and taxonomy. Am. microsc. Soc. 97: 73-88

Jellett, J. F., Scheibling, R. E. (1988a). Effect of bacterial food concentration and temperature on growth of Paramoeba invadens, a sea urchin pathogen. A.ppl. environ. Microbiol. 54: 1848-1854

Jellett, J. F, Scheibling, R. E. (1988b). Virulence of Paramoeba invadens Jones (Amoebida, Paramoebidae) from monoxenic and polyxenic culture. J. Protozool. 35: 422-424

Jellett, J. F., Scheibling, R. E., Wardlaw, A. C. (1988a). Host specificity of Paramoeba invadens, a sea urchin pathogen. In: Burke, R. D., Mladenov, P. V., Lambert, P., Parsley, R. L. (eds.) Proc 6th Intl Echinoderms Conf., Victoria, B.C., 22-28 Aug. 1987. Balkema, Rotterdam, A. A., p. $755-761$

Jellett, J. F., Wardlaw, A. C., Scheibling, R. E. (1988b). Experimental infection of the echinoid Strongylocentrotus

This article was presented by Dr M. R. Lewis, Washington,

D.C., USA droebachiensis with Paramoeba invadens: quantitative changes in the coelomic fluid. Dis. aquat. Org. 4: 149-157

Jones, G. M. (1985). Paramoeba invadens n. sp. (Amoebida: Paramoebidae), a pathogenic marine amoeba from the sea urchin Strongylocentrotus droebachiensis in Eastern. Canada. J. Protozool. 32: 564-569

Jones, G. M., Scheibling, R. E. (1985). Paramoeba sp. (Amoebida, Paramoebidae) as the possible causative agent of sea urchin mass mortality in Nova Scotia. J. Parasitol. 71: 559-565

Jones, G. M. Scheibling, R. E., Hebda, A. J., Miller, R. J. (1985). Amoebae in tissues of diseased echinoids (Strongylocentrotus droebachiensis) in Nova Scotia. In: Keegan, B. F., O'Connor, B.D.S. (eds.) Proc. 5th Intl. Echinoderms Conf., Galway, 24-29 Sept. 1984. Balkema, Rotterdam, A. A., p. 289-293

Miller, R. J., Colodey, A. G. (1983). Widespread mass mortalities of the green sea urchin in Nova Scotia, Canada. Mar. Biol. 73: 263-267

Page, F. C. (1970). Two new species of Paramoeba from Maine. J. Protozool. 17: 421-427

Page, F. C. (1973). Paramoeba: a common marine genus. Hydrobiologia 41: 183-188

Page, F. C. (1976). Some comparative notes on the occurrence of Gymnamoebea (Protozoa: Sarcodina) in British and American habitats. Trans. Am. micros. Soc. 95: 385-394

Page, F. C. (1983). Marine Gymnamoebae. Institute of Terrestrial Ecology, Cambridge

Rogerson, A. (1988). DAPI-staining for the rapid examination of nuclei and parasomes in marine gymnamoebae. Archiv. Protistenk. (in press)

Sawyer, T. K. (1980). Marine amoebae from clean and stressed bottom sediments of the Atlantic ocean and the Gulf of Mexico. J. Protozool. 27: 13-32

Scheibling, R. E. (1988). Microbial control of sea urchins: Achilles' Heel or Pandora's Box? In: Burke, R. D., Mladenov, P. V., Lambert, P., Parsley, R. L. (eds.) Proc. 6th Intl Echinoderms Conf., Victoria, B.C., 22-28 Aug. 1987. Balkema, Rotterdam, A. A., p. 745-754

Scheibling, R. E., Stephenson, R. L. (1984). Mass mortaliies of Strongylocentrotus droebachiensis (Echinodermata: Echinoidea) off Nova Scotia. Mar. Biol. 78: 153-164

Sprague, V., Beckett, R. L., Sawyer, T K. (1969). A new species of Paramoeba (Amoebida, Paramoebidae) parasitic in the blue crab Callinectes sapidus. J. Invert. Pathol. 14: $167-174$

Manuscript first received: June 17, 1988

Revised version accepted: May 10, 1989 